\title{
Incidence of Congenital Hypothyroidism in the Newborn of A Tertiary Hospital in Southern Bangladesh
}

\author{
CH RASUL ${ }^{1}$, SN LUCKY ${ }^{2}$, SR MIAH ${ }^{3}$, F MOSLEM $^{4}$
}

\begin{abstract}
Background: Congenital hypothyroidism is the commonest preventable cause of mental retardation. It is more prevalent in endemic goiter regions like Bangladesh. But magnitude of the problem has not been studied at national level.

Objective: To detect the incidence of congenital hypothyroidism among the newborn delivered in Khulna Medical College Hospital in southern part of Bangladesh and to rationalize the development of neonatal screening program.

Methodology: All the living newborns delivered between Oct '01 to June '05 in Khulna Medical College Hospital were included in the study. After taking the relevant information from mother, cord blood sample were collected from the newborn within 24 hours of birth and kept in freezer. At the end of collection of each two month, the lot of blood sample was sent to the laboratory of Institute of Nuclear Medicine, Dhaka for radioimmunoassay of TSH. Potential cases with TSH value above $10 \mathrm{MIU} / \mathrm{L}$ were recalled for thyroid function test for confirmation of diagnosis.

Results: After discarding unsatisfactory samples, 1353 samples were assayed for TSH. Among the study population $88.2 \%$ hailed from Khulna district and the rest of the cases came from neighboring districts. Male to female ratio was 1.2:1. Regarding the birth weight $33.4 \%$ babies were of low birth weight. TSH above $10 \mathrm{MIU} / \mathrm{L}$ were found in 35 babies among whom one baby was hypothyroid and the other member of the twin was also hypothyroid although the TSH level was below $10 \mathrm{MIU} / \mathrm{L}$. Thus incidence of congenital hypothyroidism was 1.5 per thousand living newborn among the studied cases.

Conclusion: The incidence of congenital hypothyroidism in southern part of the country is quite high in relation to global incidence. Although this is not the national picture but the high figure is alarming. So, neonatal screening program should be implemented as soon as possible to find out the real case burden in the community and thereby to take care of them and reduce the number of mentally retarded children in our country.
\end{abstract}

Key words: Congenital hypothyroidism, neonatal screening, mental retardation.

\section{Introduction}

Congenital hypothyroidism $(\mathrm{CH})$ is the most common congenital metabolic disorder seen in the newborn (1 in 4,000 births) $)^{1}$. It causes irreversible mental and physical disability if remains undetected and/or

1. Professor of Paediatrics, Khulna Medical College

2. Associate Professor of Obs \& Gynae, Khulna Medical College

3. Senior Medical Officer, Nuclear Medicine Centre, Khulna

4. Director (Retd), Bioscience Division, Atomic Energy Commission, Dhaka

Correspondence : Prof. Choudhury Habibur Rasul untreated. Diagnosis and treatment of $\mathrm{CH}$ before 3 months are mandatory to avoid cretinism ${ }^{1}$.

lodine deficiency is the most important and easily preventable cause of mental retardation. Globally about $10 \%$ population are suffering from iodine deficiency disorder and lack of iodine in mother leads to 30,000 still birth and $120,000 \mathrm{CH}$ in infants ${ }^{2}$. Bangladesh is known to be one hyperendemic zone for iodine deficiency. Goitre and other iodine deficiency disorder are very common in our country. The national 
survey for lodine Deficiency Disease in 1993 shows that the incidence of cretinism is $0.5 \%$ in our country ${ }^{3}$. But it was thought that the incidence would be much higher and one small study done at institute of nuclear medicine, Dhaka showed the prevalence rate of $\mathrm{CH}$ in Bangladesh as $0.9 \%$ which is a cause of concern for Physicians ${ }^{4,5}$.

In Bangladesh, there are few institute based reports on thyroid disorder. In a recent community based study in southern part of Bangladesh revealed that $3.3 \%$ of schoolgoing children are suffering from thyroid insufficiency including hypothyroidism and subclinical hypothyroidism ${ }^{6}$.

Neonatal screening program for $\mathrm{CH}$ is highly cost effective for a nation because it prevents the mentally retarded persons ${ }^{7}$. Therefore, screening program has become a routine practice in all developed countries and many developing countries in South East Asia have adopted neonatal screening for $\mathrm{CH}$ as an essential part of their health services ${ }^{8}$.

The objective of this study was to evaluate the situation of $\mathrm{CH}$ in southern part of Bangladesh to rationalize the importance of neonatal screening program in this part of the country.

\section{Materials and Methods}

Place and population: This study was carried out in Khulna Medical College Hospital $(\mathrm{KMCH})$ jointly by the Department of Obstetrics and Gynaecology, Department of Child Health and Center for Nuclear Medicine in Collaboration with Institute of Nuclear Medicine, Dhaka. Period of study was 45 months extending from October'01 to June'05. Newborn infants of both sexes aged between 0 to 24 hours delivered in hospital during that period were included in the study. Although blood sample for the procedure can be taken upto 120 hours of birth, heel prick causing discomfort was avoided. Two doctors in each year had given voluntary service for this study. Detailed information including the history and clinical findings were recorded in a predesigned clinical format in order to detect presdisposing factors in relation to hypothyroidism.

Methods of sample collection:

a) A drop of blood from baby's cord was put to each circle of filter paper and Five circles were filled in similar way. b) After collection, filter paper was dried in open air for 30 minutes; it was labeled for identification and kept in normal refrigerator $\left(2-8^{\circ} \mathrm{C}\right)$.

c) At the end of two months collected samples were sent to Dhaka in the laboratory of institute of nuclear medicine for estimation of TSH. The reports were sent back within two weeks.

Lab Test: In this method two antibodies are used against different portions of same antigen. Polyclonal antibody is coupled with magnetic iron oxide particle and monoclonal antibody is coupled with 1-125. Thus when an antigen is present in the test material, it simultaneously binds with both antibodies in a double site sandwich fashion. The formed antigen-antibody complex is separated by placing the assay tubes in magnetic separator and decanting the supernatant. The radioactivity of tracer in the tube is directly proportional to the concentration of TSH in the specimen.

The TSH level above 10 MIU/L were considered as significant since the previous small scale studies in Bangladesh revealed no case with $\mathrm{TSH}>20 \mathrm{MIU} / \mathrm{L}^{3}$. The babies having significant TSH level were recalled for final diagnosis by doing thyroid function test (T3, T4 \& TSH) by standard method. The diagnosed cases were treated with levothyroxin (10-12 $\mu \mathrm{g} / \mathrm{kg} /$ day) and followed up at monthly interval to monitor the neurodevelopmental outcome for one year. Search for cause of hypothyroidism (Scintigraphy, ultrasonography, Tb antibody) has not been done in this study.

\section{Results}

During forty five months of study, cord blood were collected from 1500 cases of live newborn. Faulty technique in blood collection led to laboratory rejection of 147 samples. Thus, 1353 cases were included in the screening program. Majority of the newborn were male and the male female ratio was 1.2:1 (Table I).

Table I

Distribution Residence of Newborn on locality \& gender

\begin{tabular}{lccc}
\hline Residence & Male & Female & Total (\%) \\
\hline Khulna & 651 & 542 & $1193(88.2)$ \\
Neighboring districts* & 86 & 74 & $160(11.8)$ \\
\hline Total & 737 & 616 & $1353(100)$ \\
\hline
\end{tabular}

* Neighboring districts- Bagerhat, Satkhira, Jessore and Narail 
Most of the patients (88.2\%) were from Khulna city and adjacent villages within Khulna district except a few $(11.8 \%)$ from neighboring districts such as Bagerhat, Satkhira, Jessore and Narail. The sample population by it's distribution represents Khulna division.

Majority (57.5\%) of mothers in this study belonged to the age group of 15 to 25 years and only $8(0.6 \%)$ mothers were below 15 years of age. Profile of newborn in relation to birth weight is shown in Table-II. Among the newborns, 433 were low birth weight and 19 were very low birth weight. Mean TSH level was lower in low birth weight babies in comparison to higher birth weight babies.

Table II

TSH level in relation to birth weight of the baby $(n=1353)$

\begin{tabular}{lcc}
\hline Birth weight $(\mathrm{kg})$ & Number (\%) & Mean TSH level (MIU/L) \\
\hline$<1.5$ & $19(1.5)$ & 2.7 \\
$1.5-2.5$ & $433(31.9)$ & 2.5 \\
$2.5-3.5$ & $822(60.7)$ & 3.4 \\
$>3.5$ & $79(5.9)$ & 3.3 \\
\hline
\end{tabular}

TSH level were divided into three categories (Table-III). Higher level (10-20) was found in thirty five babies and all were recalled for thyroid function. Among them one baby was found hypothyroid (TSH-17.6). Since he was a member of the twin, high index of suspicion prompted to test the other sibling and hypothyroidism (TSH-8.1) was detected as well. No baby was found to have TSH level above $20 \mathrm{MIU} / \mathrm{L}$.

Table III

Congenital Hypothyroidism in relation to TSH level $(n=1315)$

\begin{tabular}{lcccc}
\hline $\begin{array}{l}\text { TSH level } \\
\text { MIU/L }\end{array}$ & Number & Percent & $\begin{array}{c}\text { Mean } \pm \text { SD } \\
\text { MIU/L }\end{array}$ & CH \\
\hline Upto10 & 1318 & 97.4 & & 1 \\
$>10-20$ & 35 & 2.5 & $3.1 \pm 2.4$ & 1 \\
$>20$ & 0 & 0 & & 0 \\
\hline
\end{tabular}

Two out of 1353 newborn were detected as a sufferer of congenital hypothyroidism $(0.15 \%)$ Twins were hailing from Bagerhat, the adjacent district of Khulna. The mother was 24 years of age having no sign or drug history of hypo or hyperthyroidism. Both the cases were of low birth weight (LBW) babies. At birth, no abnormal sign was noted in them.

Table IV

Profile of Congenital Hypothyroidism cases

\begin{tabular}{|c|c|c|c|c|c|c|c|}
\hline $\begin{array}{l}\text { Case } \\
\text { No }\end{array}$ & $\begin{array}{l}\text { Home } \\
\text { district }\end{array}$ & $\begin{array}{l}\text { Date of } \\
\text { Birth }\end{array}$ & $\begin{array}{l}\text { Mothers } \\
\text { name \& age }\end{array}$ & Sex & Wt $(\mathrm{Kg})$ & $\begin{array}{l}\text { TSH MIU/L } \\
\text { screen }\end{array}$ & $\begin{array}{l}\text { Thy Func test (Norm) } \\
\text { T3 -(1.5-3.5 nm/L) }\end{array}$ \\
\hline \multirow{2}{*}{ No } & & & & & & & T4- (54-173 nm/L) \\
\hline & & & & & & & TSH- (0.3-5 MIU/L) \\
\hline
\end{tabular}

\begin{tabular}{|c|c|c|c|c|c|c|c|}
\hline & & & Jahera & & & & T3-1.5 \\
\hline 1 & Bagerhat & 01/06/02 & (24 yrs) & M & 2.3 & 17.6 & T4-27.5 \\
\hline
\end{tabular}

Jahera

T3-1.9

$\begin{array}{llllllll}2 & \text { Bagerhat } & 01 / 06 / 02 & (24 \mathrm{yrs}) & \mathrm{F} & 2.2 & 8.7 & \mathrm{~T} 4-32.8\end{array}$




\section{Discussion}

Congenital hypothyroidism identified by newborn screening has favorable outcome but IQ reduction and persistent cognitive deficit are reported in many studies $^{9}$. In UK, screening for $\mathrm{CH}$ was introduced in 1981 and the program has been successful in identifying infants before irreversible neurological damage has occurred thereby preventing lifelong disability ${ }^{10}$. Transient hypothyroxinemia occurs up to 6 months in infants who are born to mothers with poorly controlled graves disease. The central hypothyroidism may present for short term or long term. However, TSH based neonatal screening can not detect central hypothyroidism ${ }^{11}$. In premature babies thyroxin level is low and cause is multifactorial. These are loss of maternal $T_{4}$ contribution, immaturity of the hypothalamic pituitary axis, unresponsiveness of thyroid gland to TSH and immaturity of peripheral tissue deiodination ${ }^{12}$.

Most North American programs used a two tiered laboratory approach. An initial filter paper blood spot $\mathrm{T}_{4}$ measurment is followed by a measurement of TSH in the filter paper specimen with low $T_{4}$ values. This can identify thyroxin binding globulin deficiency, hypothalamic pituitary hypothyroidism but recall rate in this approach $(0.30 \%)$ is quite high. A majority of European and Japanese program favours screening by means of primary TSH measurement supplemented by $T_{4}$ determination for those infants with elevated TSH values. With this approach infants with TBG (thyroxin binding globulin) deficiency, hypothalamic pituitary hypothyroidism and hypothyroxinemia with delayed TSH elevation will be missed however the recall rate is less $(0.05 \%)$. Combined T4 and TSH estimation is the best method but until its availability there is limitations of each method. Even in the absence of technical and human error studies suggested that $5-10 \%$ of newborn with $\mathrm{CH}$ have normal screening hormone concentration regardless of the type of approach used ${ }^{2,3}$.

Standard cut off level for thyroid function test is 20 MIU/L but it was set at $10 \mathrm{MIU} / \mathrm{L}$ in the present study in the light of previous national survey result ${ }^{3,4}$. The set level resulted in recall of 35 babies (2.6\%). In no case TSH> $20 \mathrm{MIU} / \mathrm{L}$ was found.

Pregnant mothers from neighboring district were $11.8 \%$. Regarding the characterestics of mother and babies it was observed that $33.4 \%$ of babies were of low birth weight which was much lower than national figure $(45-47 \%)^{13}$. Even though there is no direct relationship between birth weight and TSH level it was found that TSH level was low in Low birth weight babies. The incidence of $\mathrm{CH}$ in our study $(0.15 \%)$ is 1.5 in 1000 live births which is quite high in comparison to global standard. Both the cases of $\mathrm{CH}$ in this study were of low birth weight although the mothers were of normal age group.

In America (USA-1995), $\mathrm{CH}$ is $1: 4,000$ but it is more prevalent in native American infants and less in black Africans and females are affected twice as common as males, in Europe (England-1991) it is 1:2500, in the opposite side of the globe (Australia-1992) it is $1: 3,500$ and in Asia (Malaysia-1995) it is $1: 3,000^{3}$. No major community based studies has been done before in Bangladesh but prevalence of cretinism was found as $0.6 \%$ in hyperendemic zone ${ }^{5}$.

The principal limitation of our study was the population size which should have been much higher for focusing the true incidence of hypothyrodism. The hospital delivery rate of in $\mathrm{KMCH}$ is much higher but lack of manpower and financial support were the deterrent for collecting large number of samples. Moreover, while sample collection was easy at birth table, mother refused to give blood on the next day to avoid further prick thus many babies were missed as our study cases.

In conclusion, the incidence of congenital hypothyroidism in southern part of Bangladesh is quite high and screening for $\mathrm{CH}$ could be highly cost effective. A nation wide survey is necessary before initiating this screening programme in the country.

\section{References}

1. Fisher DA. Disorders of the thyroid in the newborn and infant. In: Sperling M, editor. Pediatric Endrorinology. Philadelphia: WB Saunders Company; 1996. P. 51-53.

2. American Academy of Pediatrics and American Thyroid Association. Newborn screening for congenital hypothyroidism : recommended guidelines. Pediatrics 1993; 91: 1203.

3. Institute of Nuclear Medicine. Proceedings of National seminar on congenital hypothyroidism. Dhaka. Atomic Energy Centre 18 June, 2000.

4. Siddiq SK, Ahmed T, Hoque R, Yasmin S, Ahmed F, Hussain M. Spectrum of thyroid disorders observed in the Institute of Nuclear Medicine. Bang Med J 1992; 21: 71-74. 
5. Yousuf HKM, Salamatullah Q, Islam MN, Hoque T, Baguer M, Pandav CS. Report of iodine deficiency disorder survey in Bangladesh, UNICEF, 2003.

6. Miah SR, Rasul CH, Moslem F. Study report on thyroid disorders in children, Khulna. Centre for Nuclear Medicine Research Report; 2003.

7. Heyerdah IS, Kase BF, Lie SO. Intellectual development in children with congenital hypothyroidism in relation to recommended thyroxin treatment. J Pediatr 1991; 118: 850-57.

8. Bhasin SK, Kumar P, Dubey KK. Comparison of urinary iodine excretion and goitre survey to determine the prevalence of iodine deficiency. Ind Pediatr 2001; 38: 901-05.
9. Rovet JF. Children with congenital hypothyroidism and their sibling- Do they really differ? Pediatrics 2005; 115: 52-57.

10. Elliman DAC, Dezateux C, Bedford HE. Newborn and childhood screening program: criteria, evidence and current policy. Arch Dis Child 2002; 87: F6-9.

11. Higuchi R, Miyawaki M, Keemagai T, Okutani T, Shima $\mathrm{Y}$, Yoshiano $\mathrm{M}$, et al. Central hypothyroidism in infants who were born to mothers with thyrotoxicosis. Pediatrics 2005; 115: e 623-25.

12. Stuart ALO. Neonatal thyroid disorders. Arch Dis child 2002; 87: F165-71.

13. Rahaman SA. Incidence of low birth weight in term and preterm babies in institutional deliveries in Dhaka city. Bang J Child Health 1992; 16: 79-83. 